\title{
Design of a Polarization Maintaining Large Negative Dispersion PCF Using Rectangular Lattice
}

\author{
Sharafat Ali, Nasim Ahmed, Monirul Islam, S. A. Aljunid, R. B. Ahmad, H. Jaman, and S. Habib
}

\begin{abstract}
In this paper, we demonstrate a new \& simple rectangular photonic crystal fiber (RPCF) for high negative dispersion covering the $E$ to $U$ communication band with ultra-high birefringence, large nonlinearity. According to the simulation results, the designed fiber shows negative dispersion coefficient of -776 to $-1591 \mathrm{ps} /(\mathrm{nm} . \mathrm{km})$ over $E$ to $L$ communication bands with the relative dispersion slope (RDS) is perfectly matched to that of a single mode fiber. In addition, the proposed RPCF offers a high value of birefringence $2.97 \times 10-2$ and a large nonlinear coefficient of $44.5 \mathrm{~W}-1 \mathrm{~km}-1$, both at the operating wavelength of $1550 \mathrm{~nm}$. Moreover, the proposed RPCF achieved two zero-dispersion wavelengths in the visible and near IR regions for both of the $x$ and $y$ polarization modes.
\end{abstract}

Index Terms-Photonic crystal fiber, negative dispersion, high birefringence, rectangular lattice.

\section{INTRODUCTION}

The photonic crystal fiber (PCF) is silica air hole micro-structured optical fiber that has attracted a considerable amount of attention in recent years [1], [2]. Photonic crystal fibers show different optical properties such as high nonlinearity [2], [3], high birefringence [4], polarization-maintenance [5], [6], large effective mode area [7], dispersion characteristics [8]-[10] and vice versa by tuning the air hole size and position in the fiber. Due to their unique optical features, flexibility of design researchers have found significant applications of PCFs in various field such as telecommunication [11], nonlinear optical fibers, high power lasers, chemical and biological sensing [11], [12] etc. PCFs can be made highly birefringent by tuning the air hole parameters along two orthogonal a1xis [13] such as by creating asymmetric core design [14]. In many sensing applications birefringence is certainly a vital property of the fiber where a high birefringence is often important [15], [16]. In long distance fiber communication, dispersion needed to be compensated for suppress the broadening of pulse [16], [17]. Thus, to compensate the dispersion of the main fiber cable line we need a highly negative dispersion fiber with matched RDS [12]. In this paper, we present a rectangular cladding design with artificially defected core for high birefringence PCF with high nonlinearity and high negative

Manuscript received May 16, 2016; revised January 15, 2017.

Sharafat Ali, Nasim Ahmed, Monirul Islam, S. A. Aljunid and R. B. Ahmad are with the School of Computer \& Communication Engineering, University Malaysia Perlis, Pauh, 02600 Arau, Perlis, Malaysia (e-mail: sharafat.ali@ieee.org, nasim@theiet.org, s.m.1979@ieee.org).

J. Hasan and S. Habib are with the Department of Electrical \& Electronic Engineering, Rajshahi University of Engineering \& Technology, Rajshahi 6204, Bangladesh. dispersion.

To control the optical properties, different PCFs designed have been proposed in the past such as, rectangular PCFs, circular PCFs, hexagonal PCFs, square PCFs and so on. Reported [17] offers dispersion coefficient approximately $-239.51 \mathrm{ps} /(\mathrm{nm} . \mathrm{km})$ with a birefringence of $1.67 \times 10^{-2}$. In reported [18] reveals negative dispersion of $-400 \mathrm{ps} /(\mathrm{nm} . \mathrm{km})$ at the operating wavelength of $1550 \mathrm{~nm}$ and they got the birefringence of $1.60 \times 10^{-2}$. In both cases the value of birefringence is low while this is an important factor nowadays for many sensing applications. In 2013, we proposed design [19] with negative dispersion coefficient of $-331 \mathrm{ps} /(\mathrm{nm} . \mathrm{km})$ and a high birefringence of $2.75 \times 10^{-2}$. This design has a good birefringence for particular sensing applications but resulted negative dispersion is only -331 $\mathrm{ps} /(\mathrm{nm} . \mathrm{km})$ which is an average value for dispersion compensation. In 2014, we proposed two more designs for similar applications [12, 20]. We used a hybrid cladding design [12] with a negative dispersion coefficient of -868 $\mathrm{ps} /(\mathrm{nm} . \mathrm{km})$ but the resulted value of birefringence is only $1.06 \times 10^{-2}$. In another proposed PCF [20] we showed a birefringence of $1.27 \times 10^{-2}$ and the value of negative dispersion was $-324 \mathrm{ps} /(\mathrm{nm} . \mathrm{km})$.

In this paper, we are proposing a rectangular PCF (RPCF) which is used to obtain a high negative dispersion of -1249 $\mathrm{ps} /(\mathrm{nm} . \mathrm{km})$ over $E$ to $\mathrm{L}$ bands and high birefringence of $2.97 \times 10^{-2}$ with high nonlinearity of $44.48 \mathrm{~W}^{-1} \mathrm{~km}^{-1}$ at the operating wavelength of $1550 \mathrm{~nm}$. We have used artificial defected core by removing several air holes from usual rectangular PCF and used only circular air hole in our design which is the main advantages of the proposed RPCF structure for design simplicity. The propose RPCF design is very easy and simple for fabrication and the resulted optical properties are also commendable than the other reported PCFs in the past. So that, the propose design is far and foremost applicable for communication systems as well as optical sensing applications.

\section{Design Methodology}

Fig. 1 shows the air hole distribution of the proposed fiber. The diameters of the air holes in the $1^{\text {st }}$ to $3^{\text {rd }}$ ring is assigned as $d_{1}, \mathrm{~d}_{2}$ and $d_{3}$ respectively while $4^{\text {th }}$ to $8^{\text {th }}$ ring is $d$. The elliptical shape is introduced in the first ring to enhance the birefringence of R-PCF. The diameter of elliptical core in $\mathrm{x}$ direction is $d_{\mathrm{xa}}$ and in y direction is $d_{\mathrm{yb}}$ and the pitch of air hole is $\Lambda$. For that convenient of obtaining higher birefringence the $1^{\text {st }}, 7^{\text {th }}, 8^{\text {th }}, 9^{\text {th }}, 15^{\text {th }}$ and $16^{\text {th }}$ air holes are omitted from the first ring which is shown in figure 1(a). The designed RPCF has a vertex angle of $22.5^{0}$ in the first ring 
from one air hole to another. The distances of the $2^{\text {nd }}$ to $8^{\text {th }}$ rings from the center of core are $2.25 \mu \mathrm{m}, 3 \mu \mathrm{m}, 3.75 \mu \mathrm{m}$, $4.25 \mu \mathrm{m}, 5 \mu \mathrm{m}, 5.75 \mu \mathrm{m}, 6.25 \mu \mathrm{m}$ along the $\mathrm{x}$-direction and the distances along the y direction are $1.5 \mu \mathrm{m}, 2.25 \mu \mathrm{m} 3 \mu \mathrm{m}$, $3.75 \mu \mathrm{m}, 4.25 \mu \mathrm{m}, 5 \mu \mathrm{m}, 5.75 \mu \mathrm{m}$. The circular air hole is used for the design that reduces the fabrication and design complexity. The diameter of the first two rings is kept larger to achieve the high negative dispersion while third ring is scaled down in order to match the value of RDS to that of a single mode fiber (SMF). To realize high birefringence, an artificial defect is created in the core region by omitting several air-holes (the dotted circle) which is shown in Fig. 1(b).

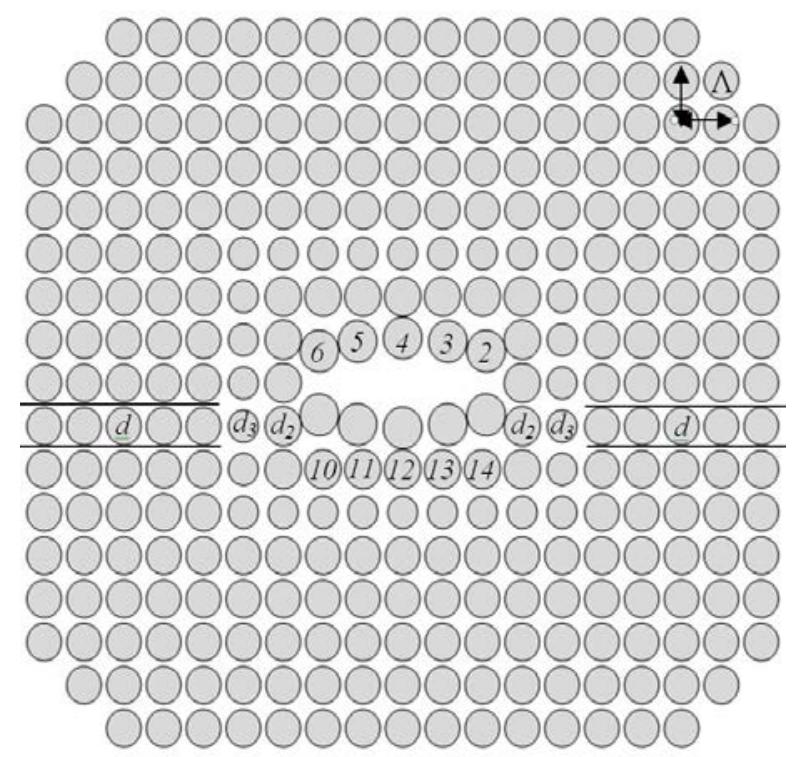

(a)

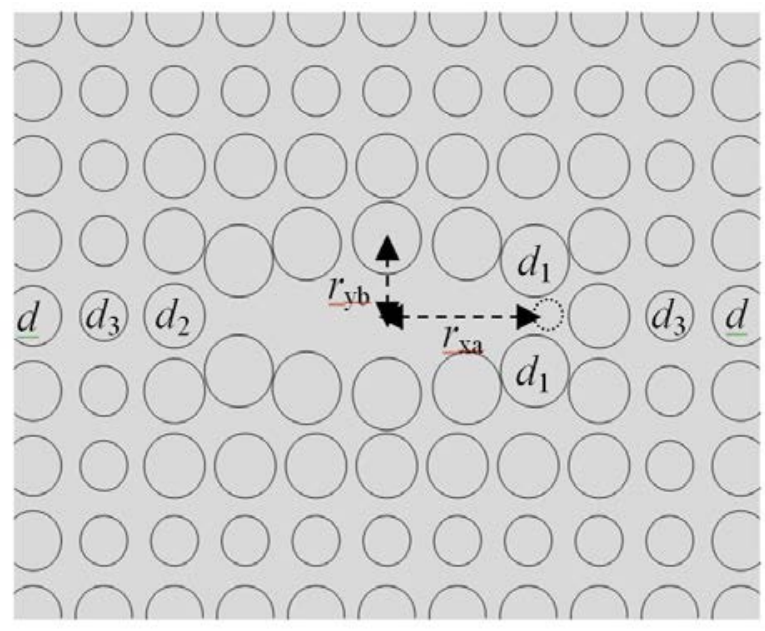

(b)

Fig. 1. Cross-section of proposed polarization maintaining photonic crystal fiber structures; (a) air hole distribution of the PCF, (b) core of the PCF.

\section{RESUlTS AND DisCUSSION}

For the calculation of the effective refractive index, dispersion, birefringence, effective area, confinement loss etc., of the proposed RPCF, we used COMSOL Multiphysics (ver. 4.2). To calculate the performance of the RPCF, a finite element method (FEM) with a circular shaped perfectly matched layers (PML) boundary is used. The value of dispersion (D), birefringence (B) and nonlinear coefficient $(\lambda)$ are determined respectively from the equations below [12];

$$
\begin{gathered}
D(\lambda)=\frac{\lambda}{c}\left(\frac{d^{2} \operatorname{Re}\left[n_{\text {eff }}\right]}{d \lambda^{2}}\right) \\
B=\left|n_{x}-n_{y}\right| \\
\gamma=\left(\frac{2 \pi n_{2}}{A_{\text {eff }} \lambda}\right) \times 10^{3} \mathrm{~W}^{-1} \mathrm{~km}^{-1}
\end{gathered}
$$

Here, $n_{\text {eff }}$ is the modal effective indexes, $\operatorname{Re}\left[n_{\text {eff }}\right]$ is the real part of $n_{\text {eff }}, \lambda$ is representing wavelength, $c$ is constant which is the velocity of light in vacuum, $\operatorname{Im}\left[n_{\text {eff }}\right]$ is the imaginary part of $n_{\text {eff, }} k$ is the wave number in free space, $n_{\mathrm{x}}$ and $n_{\mathrm{y}}$ are the effective refractive indices of $\mathrm{x}$ and $\mathrm{y}$ fundamental modes, $n_{2}$ is the nonlinear index coefficient and $A_{\text {eff }}$ is the effective area of the proposed PCF.

The fundamental mode of the optical field distributions for both the $\mathrm{x}$ and $\mathrm{y}$ polarization at the operating wavelength of $1550 \mathrm{~nm}$ are shown in Fig. 2. Simulations show that both modes are strongly confined inside high-index center core region of the PCF. Fig. 3 shows the wavelength response of the dispersion for optimum parameters. The value of dispersion is $-1249 \mathrm{ps} /(\mathrm{nm} . \mathrm{km})$ at the operating wavelength of $1550 \mathrm{~nm}$ for x polarizing mode. From the figure it can be seen that for both $\mathrm{x}$ and $\mathrm{y}$ polarizing modes the PCF provides two zero-dispersion wavelengths in the visible and near IR wavelength regions.

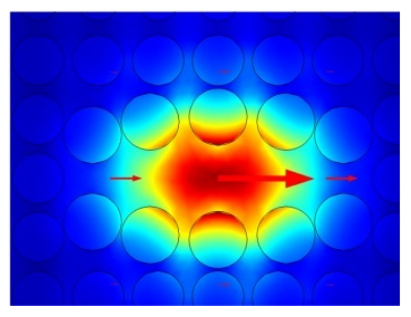

(a)

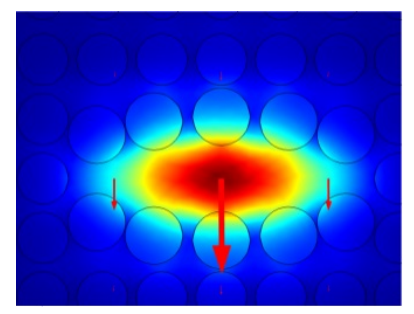

(b)
Fig. 2. Field distributions of fundamental modes for (a) x polarization and (b) y polarization at $1550 \mathrm{~nm}$.

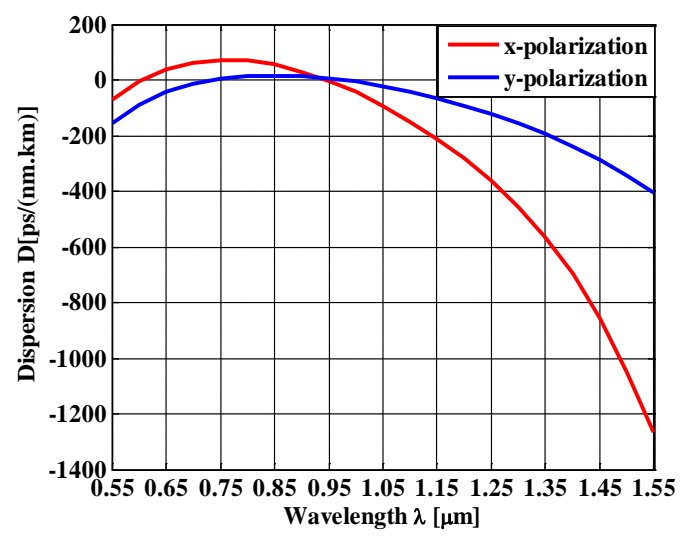

Fig. 3. Dispersion of the proposed PCF optimum design.

The difference of the effective refractive index of $x \& y$ 
polarization is defined as birefringence. In our proposed design, the artificial center core intentionally creates asymmetry that provides a large increase in birefringence value which is desirable for many polarization maintaining applications like optical sensing. We have used defective core as an ellipse, for higher birefringence and the diameter of the core is $\mathrm{d}_{\mathrm{xa}} / \Lambda=4.44$ and $\mathrm{d}_{\mathrm{yb}} / \Lambda=1.76$ which provides a high birefringence of $2.97 \times 10^{-2}$. Fig. 4 is showing the effect of pitch over (a) birefringence and (b) dispersion. It is seen from Fig. 4 that with the increase of the pitch $\Lambda$, the value of birefringence rapidly decreases as a result of index difference between two polarized axes decreases with the decreasing pitch. Nevertheless negative dispersion decreases from the optimum stage with the increase of pitch.

The birefringence at the optimum stage is $2.97 \times 10^{-2}$ where the pitch is $\Lambda=0.82 \mu \mathrm{m}$. But for the changed value of the pitch $0.85 \mu \mathrm{m}, 0.88 \mu \mathrm{m}$ and $0.90 \mu \mathrm{m}$ the birefringence values are $2.94 \times 10^{-2}, 2.88 \times 10^{-2}$ and $2.83 \times 10^{-2}$ respectively. Again The dispersion at the optimum stage is $-1249 \mathrm{ps} /(\mathrm{nm} . \mathrm{km})$ where the pitch is $\Lambda=0.82 \mu \mathrm{m}$. but the changing of pitch 0.85 $\mu \mathrm{m}, 0.88 \mu \mathrm{m}, 0.90 \mu \mathrm{m}$ the negative dispersion are-973 ps/(nm.km), $\quad-765$ ps/(nm.km), and $\quad-657$ ps/(nm.km) respectively. The birefringence and negative dispersion for the optimum stage at the operating wavelength is $2.97 \times 10^{-2}$ and $-1249 \mathrm{ps} /(\mathrm{nm} . \mathrm{km})$ which are better than previously proposed PCF designs.

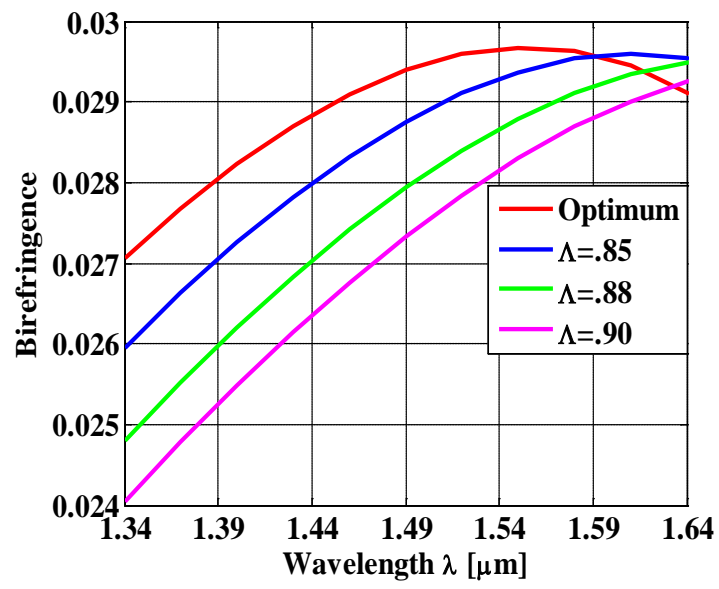

(a)

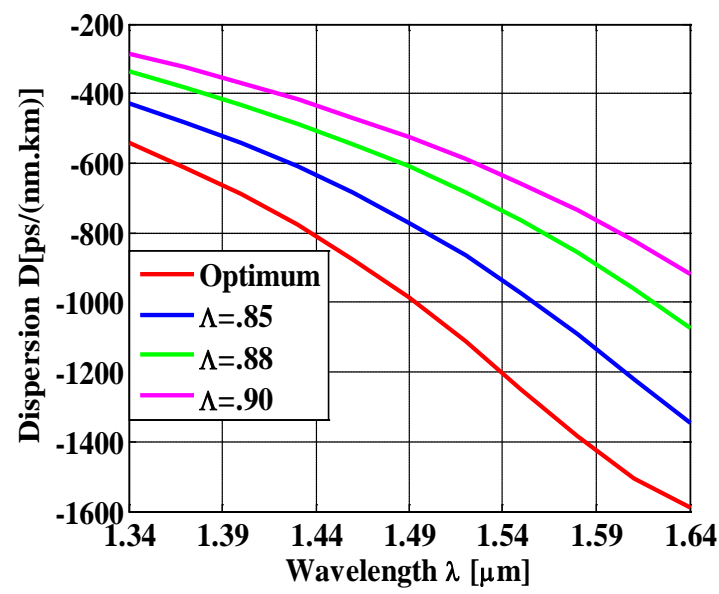

(b)

Fig. 4. Effect of pitch on (a) birefringence and (b) dispersion behavior.

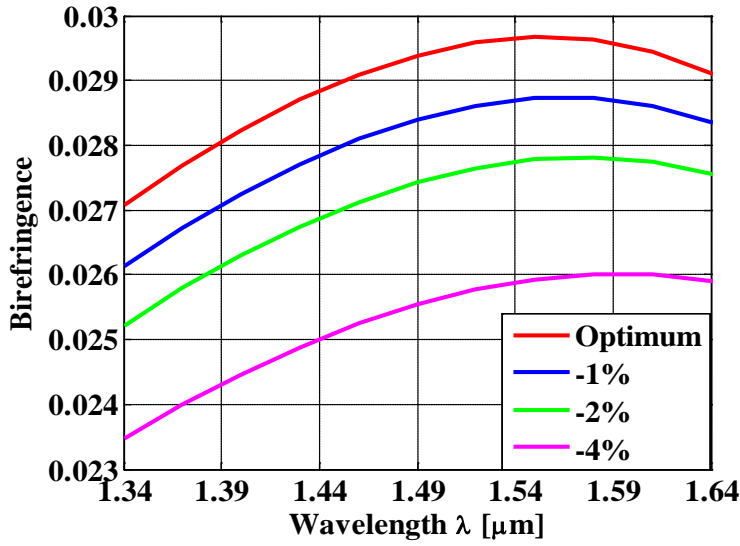

(a)

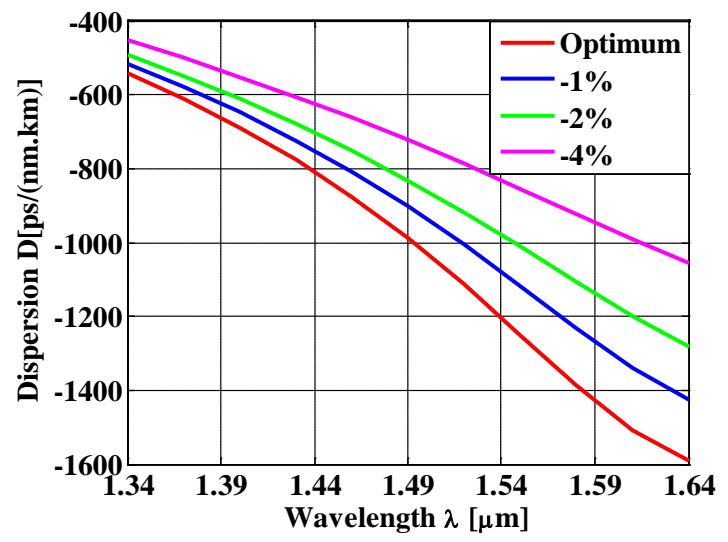

(b)

Fig. 5. Birefringence and dispersion properties of RPCF: Effect of changing 1 st ring diameter on (a) birefringence and (b) dispersion.

The changing of first ring diameter has large impact on the desired results. In our design the first ring is the shape in ellipse and is standing around the core. However we know the effect on refractive index is very high for any small change in the parameter around the core. Fig. 5 and Fig. 6 show the wavelength dependency of birefringence and dispersion of the proposed design for the x polarized mode when the first ring parameters are tuned. Simulation result shows if the diameter is decreased than optimum stage then both birefringence and dispersion decreases.

Fig. 6 shows the effect of diameter $d_{\text {ха }}$ on birefringence and dispersion behavior keeping other air hole positions unchanged. It can be seen from fig.6 that at the operating wavelength of $1550 \mathrm{~nm}$, the peak value of both the birefringence and the negative dispersion increases with the decreasing value of $d_{\text {xa }}$. Fig. 7 shows the effect of changing the diameter $d_{\mathrm{yb}}$ on birefringence and dispersion characteristics. Form this figure it can be seen that the peak value of birefringence and negative dispersion coefficient increases with the decreasing value of $d_{\mathrm{yb}}$ at the operating wavelength of $1550 \mathrm{~nm}$. Fig. 8 shows the Residual Dispersion (RD) of the RPCF for optimum parameters. It is clearly observed that the proposed RPCF is a suitable candidate for data transmission in high-bit-rate systems over E, S, C and L communication bands. To match the RDS of the proposed fiber with that of the SMF at $1550 \mathrm{~nm}$ the $3^{\text {rd }}$ ring diameter is tuned which is shown in Table I. The RDS of proposed RPCF design is $0.0036 \mathrm{~nm}^{-1}$ for the optimum parameters. 


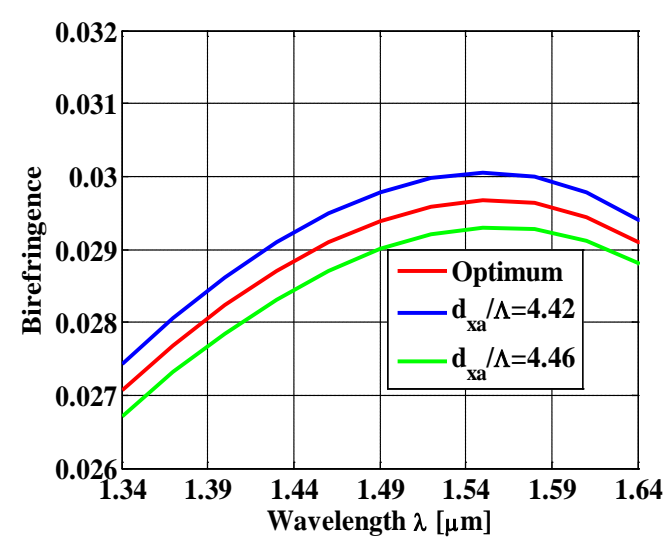

(a)

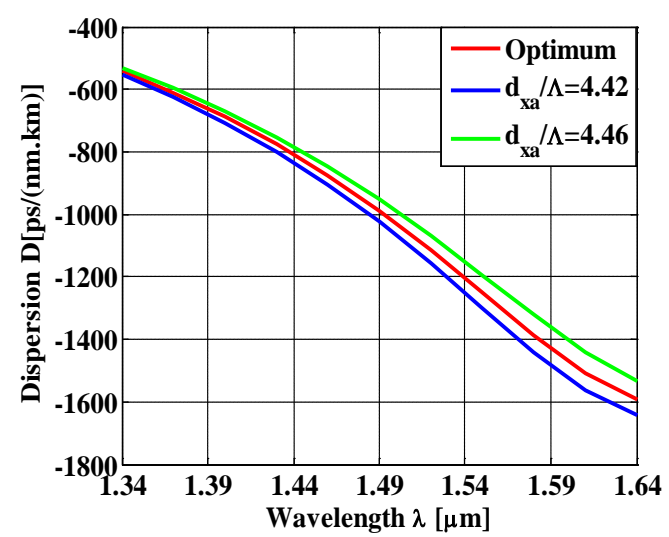

(b)

Fig. 6. Effect of varying diameter of the ellipse lattice air holes of the $x$ polarization mode on (a) Birefringence (b) Dispersion.

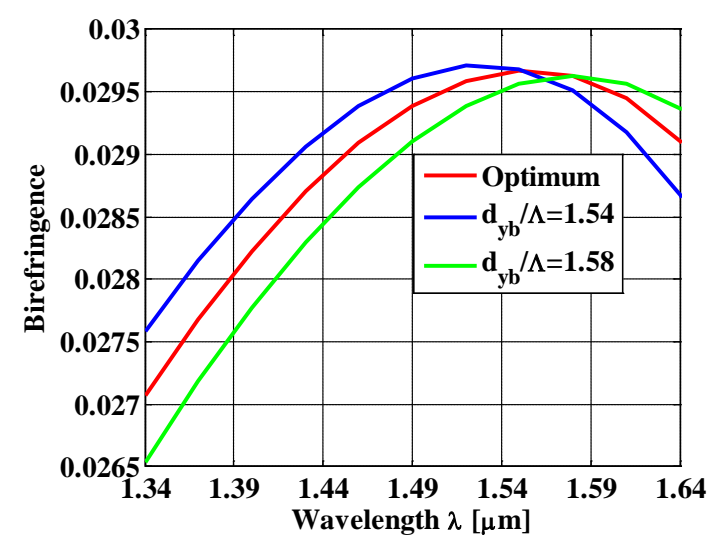

(a)

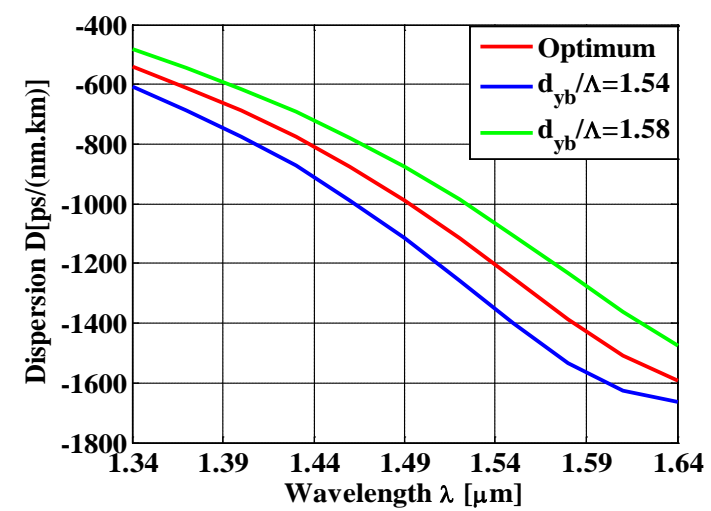

(b)

Fig. 7. Effect of varying diameter of the ellipse lattice air holes of the $y$ polarization on (a) Birefringence (b) Dispersion.

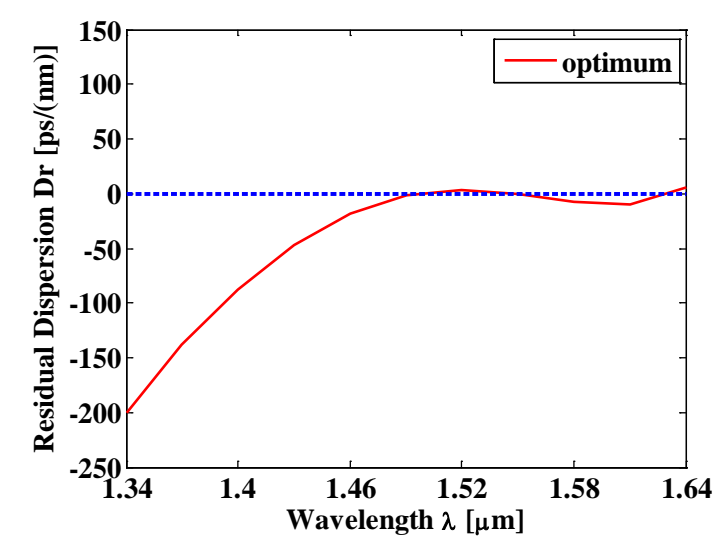

Fig. 8. The residual dispersion curve for optimum design parameters of the proposed PCF.

TABLE I: EFFECT ON RDS FOR CHANGING 3RD RING AIR HOLE DIAMETER

\begin{tabular}{cc}
\hline \hline Diameter of $3^{\text {rd }}$ ring, $d_{3}(\mu \mathrm{m})$ & $\mathrm{RDS}\left(\mathrm{nm}^{-1}\right)$ \\
\hline 0.426 & 0.0032 \\
0.418 & 0.0034 \\
0.410 & 0.0036 \\
\hline \hline
\end{tabular}

The effective area for optimum design parameters ploted in Fig. 9. At the point $1.55 \mu \mathrm{m}$ the effective area becomes 2.09 $\mu \mathrm{m}^{2}$. From the figure shows that the area is increased with increased of wavelength.

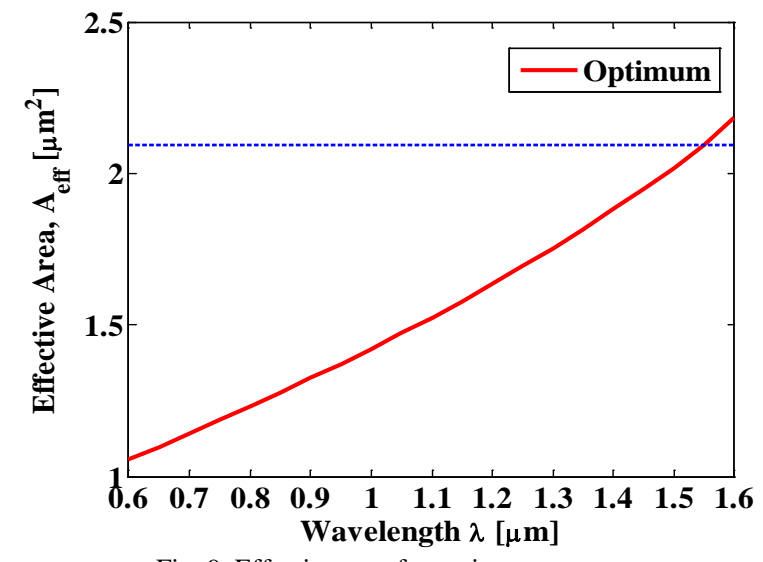

Fig. 9. Effective area for optimum parameters.

TABLE II: COMPARISON OF DIFFERENT OPTICAL PROPERTIES BETWEEN PREVIOUSLY PROPOSED PCFS AND THE PROPOSED RPCF

\begin{tabular}{ccc}
\hline \hline PCFs & $\mathrm{B}(|\mathrm{nx}-\mathrm{ny}|)$ & $\mathrm{D}(\lambda) \mathrm{ps} /(\mathrm{nm} . \mathrm{km})$ \\
\hline Ref. [12] & $1.06 \times 10^{-2}$ & -868 \\
Ref. [17] & $1.67 \times 10^{-2}$ & -239.51 \\
Ref. [18] & $1.60 \times 10^{-2}$ & -400 \\
Ref. [19] & $2.75 \times 10^{-2}$ & -331 \\
Ref. [20] & $1.27 \times 10^{-2}$ & -324 \\
Proposed RPCF & $2.97 \times 10^{-2}$ & -1249 \\
\hline \hline
\end{tabular}

Finally, a comparison is shown in Table II among properties of the discussed RPCF with some other PCF designs previously proposed for dispersion compensation and sensing application. 


\section{CONCLUSION}

We have analyzed a new RPCF design with high birefringence, large negative dispersion and high nonlinearity. A rectangular lattice structure is used to arrange the air holes in the PCF. A defected core is used in proposed RPCF to obtain high value of birefringence i.e., in the order of $10^{-2}$. The guiding properties are investigated numerically by using full-vector finite element method (FEM). In this proposed PCF we have found the birefringence value of $2.97 \times 10^{-2}$, negative dispersion of $-1249 \mathrm{ps} /(\mathrm{nm} . \mathrm{km})$ over $\mathrm{E}$ to L bands with match RDS and nonlinear coefficient of 44.5 $\left(\mathrm{W}^{-1} \mathrm{~km}^{-1}\right)$ at the operating wavelength $1550 \mathrm{~nm}$. Considering all simulation results and design simplicity we can conclude that this proposed RPCF is very good candidate for sensing and dispersion compensation applications.

\section{REFERENCES}

[1] B. Fu, S. G. Li, Y.-Y. Yao, L. Zhang, and M. Y. Zhang, "Improved high birefringence photonic crystal fibres with dispersion attened and single mode operation," Chinese Physics, vol. 20, pp. 024209-024215, 2011.

[2] K. Saitoh and M. Koshiba, "Highly nonlinear dispersion-flattened photonic crystal fibers for supercontinuum generation in the telecommunication window," Optical Express, vol. 12, pp. 2027-2032, 2004.

[3] G. P. Agarwal, Nonlinear Fiber Optics, 2nd ed. USA: Academic Press, 1995.

[4] W. J. Ju and M. S. Demokan, "Properties of a highly birefringent photonic crystal fiber," IEEE Photonic Technology Letters, vol. 15, pp. 1375-1377, 2003.

[5] H. Kubota, S. Kawanishi, S. Koyanagi, M. Tanaka, and S. Yamaguchi, "Absutly single polarization on photoniccrystel fibe," IEEE Photonic Technology Letters, vol. 16, pp. 1667-1669, 2004.

[6] W. H. Reeves, J. C. Knight, and P. St. J. Russell, "Demonstration of ultraflattened dispersion in photonic crystal fibers," Optic Express, vol. 10, pp. 609-613, 2002.

[7] A. Ferrando, Silvestre, E., Miret, J. J. and Andrés, P., "Nearly zero ultraflattened dispersion in photonic crystal fibers," Optic Letters, vol. 25, pp. 790-792, 2000.

[8] A. Ortigosa-Blanch, J. C. Knight, W. J. Wadsworth, J. Arriaga, B. J. Mangan, T. A. Birks, and P. S. J. Russell, "Highly biregringent photonic crystal fibers," Optic Letters, vol. 25, pp. 1325-1327, 2000.

[9] K. Suzuki, H. Kubita, S. Kawanishi, M. Tanaka, and M. Fujita, "Highspeed bi-directional polarization division multiplexed optical transmission in ultra low-loss $(1.3 \mathrm{~dB} / \mathrm{km})$ polarization-maintaining photonic crystal fiber," Electronics Letters, vol. 37, pp. 1399-1401, 2001.

[10] T. P. Hansen, J. Broeng, S. E. B. Libori, E. Knuders, A. Bjarklev, J. R. Jensen, and H. Simonsen, "Highly birefringent index-guiding photonic crystal fibers," IEEE Photonic Technology Letters, vol. 13, pp. 588-590, 2001.

[11] M. S. Ali, N. Ahmed, S. A. Aljunid, R. B. Ahmed, "Design of undulate cladding photonic crystal fiber for dispersion compensation over $\mathrm{E}+\mathrm{S}+\mathrm{C}+\mathrm{L}$ communication bands and sensing applications," International Journal of Microwave and Optical Technology, vol. 10, pp. 280-287, 2015.

[12] M. S. Ali, N. Ahmed, R. Ahmad, M. S. Hossain, K. M. Nasim, M. S. Habib, S. A. Aljunid, "Design of a polarization maintaining photonic crystal fiber for dispersion compensation over $\mathrm{E}+\mathrm{S}+\mathrm{C}+\mathrm{L}$ telecom bands," Ukrainian Journal Of Physical Optics, vol. 15, pp. 207-215, 2014.

[13] M. S. Habib, M. S. Rana, M. Moniruzzaman, M. S. Ali, and N. Ahmed, "Highly birefringent broadband dispersion compensating photonic crystal fiber over $\mathrm{E}+\mathrm{S}+\mathrm{C}+\mathrm{L}+\mathrm{U}$ wavelength bands," Optical Fiber Technology, vol. 20, pp. 527-532, 2014.

[14] H. Ademgil and S. Haxha, "Highly Birefringent Photonic Crystal Fibers With ultralow chromatic dispersion and low confinement losses," Journal of Lightwave Technology, vol. 26, pp. 441-448, 2008.

[15] S. Smolka, M. Barth, O. Benson, "Highly efficient fluorescent sensing with hollowcore photonic crystal fiber," Optic Express, vol. 15, pp. 12783-12791, 2007.

[16] F. Poli, A. Cucinotta, and S. Selleri, "Photonic crystal fibers, properties and applications," Springer Series in Material Science, vol. 102, 2007.

[17] B. Zsigri, J. Laegsgaard, and A. Bjarklev, "A novel photonic crystal fibre design for dispersion compensation," Journal of Optics A: Pure and Applied Optics, vol. 6, pp. 717-720, 2004.

[18] A. Agrawal, N. Kejalakshmy, J. Chen, B. M. A. Rahman, and K. T. V. Grattan, "Golden spiral photonic crystal fiber: Polarization and dispersion properties," Optic Letters, vol. 33, pp. 2716-2718, 2008.

[19] M. S. Ali, K. M. Nasim, R. Ahmad, M. A. G. Khan, and M. S. Habib, "A defected core highly birefringent dispersion compensating photonic crystal fiber," International Conference on Advances in Electrical Engineering (ICAEE 2013), pp. 100-105, 2013.

[20] M. H. Jaman, M. S. Ali, N. Ahmed, S. A. Aljunid, M. Rahman, and R. B. Ahmad, "Large negative dispersion with residual dispersion compensation over $\mathrm{E}+\mathrm{S}+\mathrm{C}+\mathrm{L}+\mathrm{U}$ wavelength bands by using single mode Hexagonal Photonic Crystal Fiber (H-PCF)," International Conference on Electronics Design (ICDE), pp. 192-197, 2014.

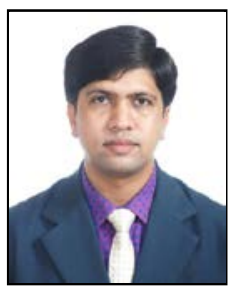

Sharafat Ali is working as a graduate assistant (GA) in the School of Computer \& Communication Engineering at University Malaysia Perlis. His general research interests lie in fiber optic communication and photonic crystal fiber. I am particularly interested in porous core fibers, dielectric terahertz waveguides, dispersion compensating fibers, nonlinear fibers, birefringent fibers in the applications of communication, sensing and so on. 